\title{
Injuries at Johannesburg high school rugby festivals
}

\author{
D Constantinou, ${ }^{1} \mathrm{MB}$ BCh, BSc (Med)(Hons), MSc (Med), FFIMS; A Bentley, ${ }^{2} \mathrm{MB}$ BCh, PhD \\ ${ }^{1}$ Centre for Exercise Science and Sports Medicine, School of Therapeutic Sciences, Faculty of Health Sciences, University of the Witwatersrand, Johannesburg, South Africa \\ ${ }^{2}$ Department of Family Medicine, School of Clinical Medicine, Faculty of Health Sciences, University of the Witwatersrand, Johannesburg, South Africa
}

Corresponding author: D Constantinou (demitri.constantinou@wits.ac.za)

\begin{abstract}
Background. Injuries occurring at the popular schoolboy rugby festivals in South Africa have not previously been evaluated. A rugby festival is a unique event with multiple matches occurring over a 5-day period and a potentially increased risk of injury compared with adult games. Objectives. To analyse the prevalence and type of injuries over 2 years of a Johannesburg High School rugby festival, to compare the injuries between the 2 years and to compare the injuries between the 3 days of the festivals.

Methods. The study design was a retrospective, descriptive and observational study. The study population were participating rugby players at the two rugby festivals in 2010 and 2011 who came to the medical tent provided. A standardised medical form was used to capture data. Results. A total of 626 players participated with 100 injury data sets analysed over the 2 years. The injury rate per player was $17 \%$ in year 1 and $15 \%$ in year 2 . There was no statistical difference $(p=0.65)$ in the injury numbers between the 2 years. The injury profiles between the respective days and between the 2 years were not statistically different. Most injuries were to the head/face (30\%), with the majority being concussion related (6\%). Tackles were the most common mechanism of injury. Overall $24 \%$ of injuries were deemed severe enough to stop the players from continuing play. Few injuries required referral for investigations or specialist physician care ( $19 \%$ and $2 \%$, respectively) and most were managed with simple first aid at the primary care level.

Conclusion. The number, nature and mechanisms of rugby injuries at this rugby festival were similar to numerous local and international studies of schoolboy rugby players. Adequate standardised record keeping is recommended to increase knowledge and monitor trends.
\end{abstract}

S Afr J Sports Med 2015;27(2):46-49. DOI:10.7196/SAJSM.596

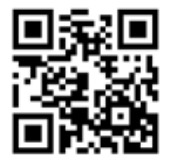

There are numerous school-level, friendly rugby competitions in South Africa (SA), of which the Easter Rugby Festivals are possibly the most popular. These are held for 3 days over the Easter weekend at a number of schools around the country, and in Gauteng three schools host Easter Rugby Festivals.

Concerns have been raised, across the world, regarding the safety of the sport due to its physical, high-impact nature and an increasing number of injuries. ${ }^{[1,2]}$ Injuries in rugby, at school and senior club level have been reported in Great Britain, Australasia and SA. ${ }^{[3-7]}$ Averages of between 6.8 and 129.8 injuries per 1000 player hours of matches occur in schoolboys. ${ }^{[4,7,8]}$ Most studies look at injuries over full seasons or a number of years and present data in differing ways such as per 10000 hours played ${ }^{[9]}$ or 1000 hours played.$^{[10]}$ Injury surveillance is important in injury prevention strategies. ${ }^{[7,11]}$ It is difficult to know how this translates to one event over 3 days of play and thus makes it difficult to plan medical services.

Most injuries reported to occur in rugby players are to soft tissue, occurring mainly to ligaments and tendons, are due mainly to collisions and occur particularly in the head, neck and lower limbs. ${ }^{[4,5]}$ Injuries are also more likely to occur at competitions compared with training periods. ${ }^{[3,4,7]}$ There are possible precipitating causes unique to schoolboys in that the boys may often be mismatched in size ${ }^{[12]}$ and experience due to the difference in pubertal growth spurts.

SA data on schoolboy rugby injuries exist ${ }^{[12,13]}$ but given the significant and ongoing changes in the rules of the game, the improved facilities for schoolboy rugby, and the recognised need for injury surveillance, an investigation into rugby injuries using the schoolboy rugby festivals as a convenient event was warranted. The objective of the research was to analyse the prevalence and type of injuries over 2 years of a Johannesburg high school rugby festival, and to specifically describe injuries (number, anatomical sites, types and severity), to compare injuries between the 2 years and compare injuries between the 3 days of the festivals.

\section{Methods}

\section{Setting}

The rugby festivals were held over 3 non-consecutive days: on the Thursday before the Christian religious holiday of Easter Friday, on the following Saturday and then on the Monday thereafter. At these festivals over 300 boys participated from 22 schools. Thirty-five matches were played for an average 35 minutes each, and each player could play between one and three matches. The refereeing was done by certified provincial referees. Fully-equipped medical facilities were available during the festivals, and with at least one medical doctor, paramedics, first aiders, a nurse and physiotherapists on duty. A local hospital with an advanced trauma unit, and fast-tracked radiograph facilities were available for referral.

\section{Study design}

The study design was a retrospective, descriptive observational study. The study population were the participating rugby players at the rugby festivals in 2010 and 2011. Inclusion criteria were all completed medical records that had adequate information of rugby-related injuries in schoolboy rugby participants at the festival. The injury recording form of the Injury International Consensus ${ }^{[14]}$ was used for 
capturing injury data. Injury severity was assessed by whether the injury was severe enough for the player to stop or be withdrawn from playing in the match where they sustained the injury; the decision was made by the medical personnel and verified by the researcher. Data were collected on: injury type and severity, anatomical site, mechanism of injury, referral to hospital or for investigations, withdrawal from play at time of injury and management. Information was obtained from the injured player and where possible verified by first aiders/paramedics, coach, parent/s and/or peers.

\section{Ethical considerations}

Permission for use of the medical records for research was granted by the host school. Ethics permission was granted by the University's Human Research Ethics Committee (medical) for Human Subjects (number M120229). Participating schools and players signed indemnities and allowed for injury recording during the rugby festivals. No identifying data were used in the analysis.

\section{Data analysis}

As there were 100 data points the number is equal to the percentage and these are used interchangeably in the results section. Percentages were used to describe categorical data and medians and confidence intervals (CIs) for numerical data. Comparative statistics for the 2 years was done using Fisher's Exact test and between the different days of the festival using non-repeated measures analysis of variance (ANOVA) tests. The data were analysed using GraphPad Prism for Windows (GraphPad Software, USA) and Statistica V12 (StatSoft Inc, USA). A level of significance of $p<0.05$ was used.

\section{Results}

In both years of the festival, 12 high schools and 10 preparatory schools participated with a total of 69 matches played (36 and 33 in 2010 and 2011, respectively). A total of 626 players participated (322 and 304 in each year, respectively) in the rugby festivals with a total of 111 injuries recorded over the 2 years. Incomplete data sets were not included ( 5 and 6 in each year, respectively) leaving a total of 100 data sets for analysis. The injury rate was 408 injuries per 10000 match hours and the injury rate per player in year $1(17 \%, 95 \%$ CI $33-84 \%)$ was not significantly different to that in year $2\left(15 \%, \chi^{2}=0.203, p=0.65\right.$, $95 \%$ CI $30-80 \%)$. Over the 35 matches there was an injury rate of 1.5 injuries per match in year 1 and 1.4 injuries per match in year 2.

The overall injuries divided by day of festival, year of festival and anatomical area are listed in Table 1. Most injuries occurred to the head and neck, followed by the lower limb and upper limb. There was no significant difference between anatomical sites of injury between the 2 years of the rugby festivals ( $p=0.64$, Fisher's exact test) nor was there any difference between respective days of the 2 years (day 1 $p=0.63$, day $2 p=0.07$, day $3 p=0.32$ Fisher's exact). There was also no significant difference in the anatomical site of injury between the 3 days of the festival ( $p=0.06, \chi^{2}$ test). Of the lateralised injuries $37 \%$ and $20 \%$ occurred on the right side and $30 \%$ and $26 \%$ on the left side (years 1 and 2 respectively), and this difference was not significantly different. The balance were not lateralised (e.g. abdomen). The majority of the rugby players ( $85 \%$ in year 1 and $78 \%$ in year 2 ) had not previously had similar injuries.

The types of injury sustained by year of festival are indicated in Fig. 1 . The majority of the injuries were to soft tissue in both years (72\% in year 1 and $77 \%$ in year 2$)$. There was a significant difference in the frequency of injury type between the years $(p=0.02)$ mainly because there were incidences of dislocations, lacerations and fractures in year 1, but not in year 2. There were no fractures of the cervical spine.

Almost half of the injuries were due to tackles with the next most common injury resulting from accidental collision (Fig. 2).

In year $1,27 \%$ of all the injured players were stopped from continuing (indicating severity) compared with $22 \%$ in year 2 . This difference was not statistically significant $\left(p=0.64, \chi^{2}\right)$. No catastrophic injuries such as severe neck injuries with neurological fallout were sustained. Most injured players were given advice on their injuries, which were relatively minor. The most common form of management was basic first aid following the RICE (rest, ice, compression and elevation) principle, which was then followed by referral for soft tissue

Table 1. Injuries by day of festival, year of festival and anatomical area

\begin{tabular}{|c|c|c|c|c|c|c|c|c|c|c|c|c|c|c|c|c|c|}
\hline & \multicolumn{2}{|c|}{ Head/neck $(n=42)$} & \multicolumn{3}{|c|}{ Torso $(n=7)$} & \multicolumn{5}{|c|}{ Upper $\operatorname{limb}(n=22)$} & \multicolumn{6}{|c|}{ Lower $\operatorname{limb}(n=29)$} & \multirow[b]{2}{*}{ 푱 } \\
\hline & 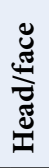 & $\begin{array}{l}\text { Ü } \\
\text { Z }\end{array}$ & ఏ & 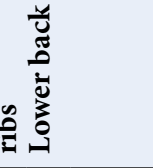 & $\frac{\frac{\dot{\theta}}{0}}{\frac{0}{0}}$ & 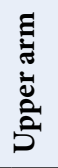 & $\begin{array}{l}3 \\
0 \\
\text { 모 }\end{array}$ & 胥 & $\stackrel{5}{3}$ & $\underset{\Xi}{\overparen{I}}$ & 包 & $\underset{\Xi}{\Xi}$ & 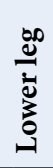 & $\frac{0}{3}$ & 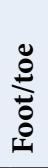 & 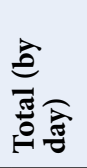 & \\
\hline \multicolumn{18}{|l|}{ Year 1} \\
\hline Day 1 & 6 & & & 1 & & & & & & 1 & & 1 & & 1 & & 10 & \\
\hline Day 2 & 2 & 3 & 3 & 1 & 2 & & 1 & & & 4 & 2 & 1 & 2 & 2 & 1 & 24 & $n=54$ \\
\hline Day 3 & 4 & 1 & & & 2 & & & & & 3 & 1 & 6 & & 1 & 2 & 20 & \\
\hline \multicolumn{18}{|l|}{ Year 2} \\
\hline Day 1 & 8 & 2 & & & & 1 & 1 & 2 & & & & 2 & & & & 16 & \\
\hline Day 2 & 5 & 4 & 1 & & & & & 2 & 1 & & 1 & 1 & & & & 15 & $n=46$ \\
\hline Day 3 & 5 & 2 & 1 & & & 1 & 1 & & & & 1 & 4 & & & & 15 & \\
\hline Total & 30 & 12 & 5 & 2 & 4 & 2 & 3 & 4 & 1 & 8 & 5 & 15 & 2 & 4 & 3 & & 100 \\
\hline
\end{tabular}




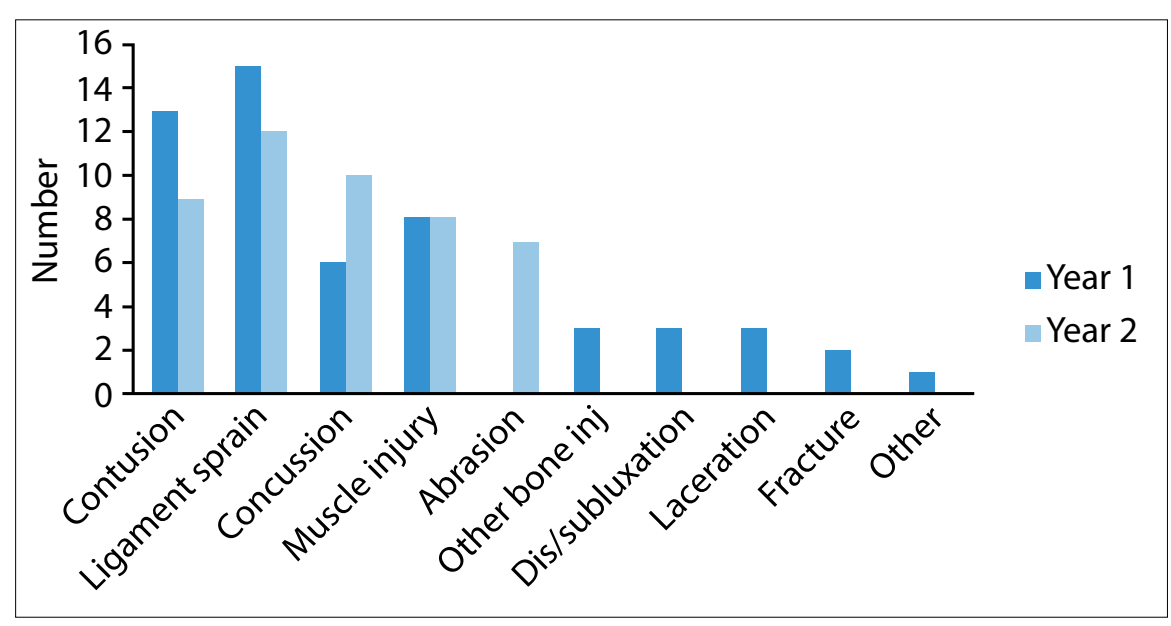

Fig. 1. Injury types and frequencies in years 1 and 2. (Inj = injuries; dis = dislocation.)

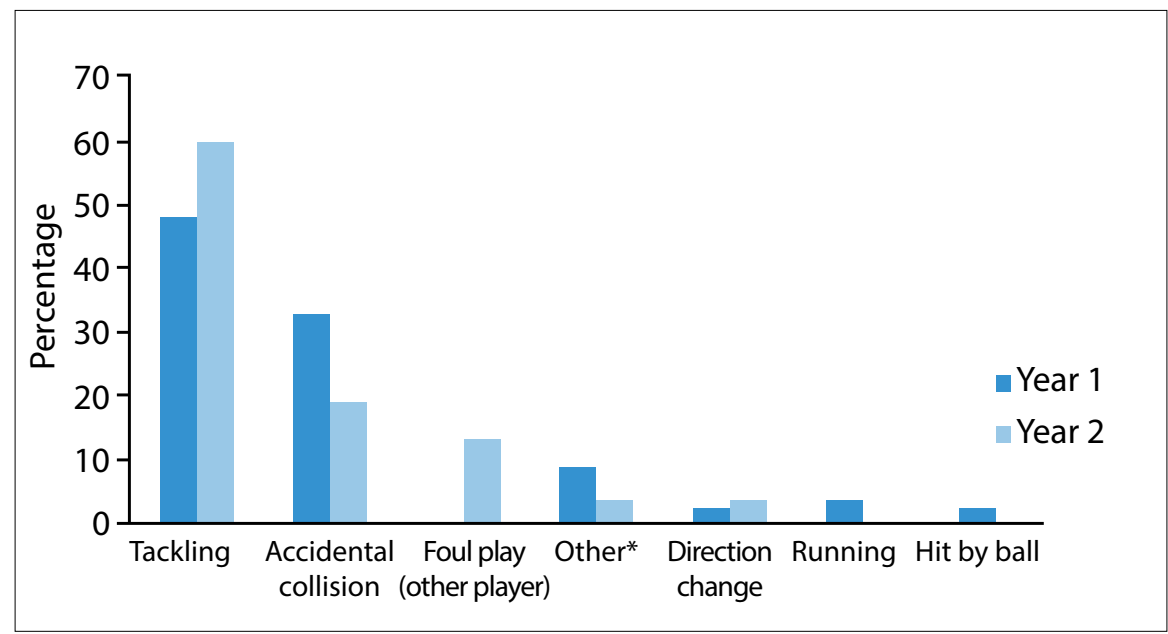

Fig. 2. Mechanisms of injury over the two years of the rugby festival. $\left({ }^{*}\right.$ For example non-contact (falling).)

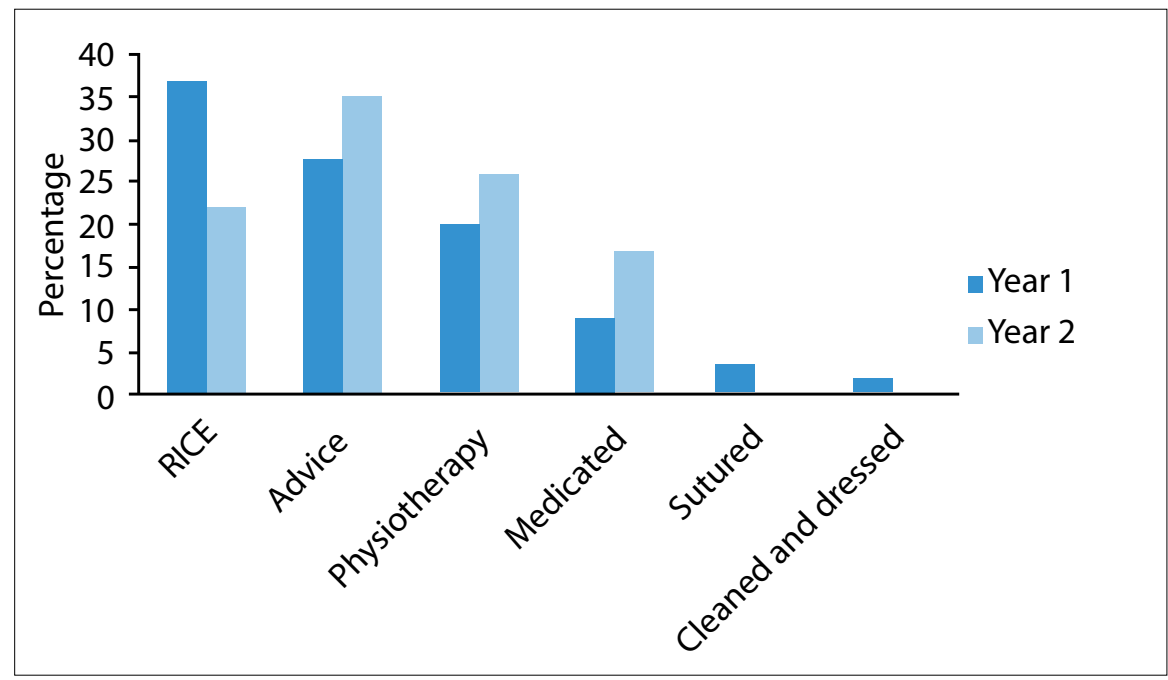

Fig. 3. Management of injuries after assessment (RICE).

therapy using physiotherapy and medications that were non-steroidal anti-inflammatories or analgesics. Treatment may not have been mutually exclusive, for example, there may have been both RICE and physiotherapy. There was no significant difference between the two years in management of injuries $(p=0.58)$.

There was a significant difference in referrals for radiographs between the 2 years $\left(p=0.01, \chi^{2}\right)$. Nine players were referred for radiographs in year 1 and 19 in year 2 with only one schoolboy referred for a magnetic resonance imaging scan in year 1. One-third of these referrals were for suspected neck injuries and the remainder for suspected fractures, avulsion injuries and dislocations of peripheral joints. Two of the players had fractures confirmed and were then immobilised and referred to orthopaedic surgeons for further management.

\section{Discussion}

Overall for the 2 years and 6 days of the Easter Rugby Festivals, there were 100 injuries most of which were to the head and neck, to soft tissue and usually did not prevent the player returning to the game. As expected most injuries resulted from tackles and accidental collisions. There were no differences in anatomical area or type of injury between days of the festival or years of festival.

There were limitations to this study, particularly owing to the method of reporting injuries. The data collection forms used a standardised international form ${ }^{[14]}$ that had flaws; there was no place for side dominance of the players, nor their age. Details of how many matches and how much time each individual player had played would also add value. Thus individual risk determination where exposure in participation is important could not be assessed. Some injured players may have not presented to the available medical centre at the festivals for assessment or management. There may also be faults in the mechanism of injury where they do not want to report the truth as very few reported foul play, which may not be a true reflection. Another limitation is that the results cannot be extended to all schoolboy rugby festivals and schoolboy rugby competitions, or even playing in normal matches taking place weekly with adequate time to recover between matches. These festivals were hosted by a school that had resources with respect to funding, access to expert medical care with good facilities, and access to qualified referees.

Over the 2 years in this study a total of 100 injuries were recorded over the two rugby festivals, played over 6 days. Thus an average 
of just over 16 injuries per day was evident. The injury frequency found in this study is not unlike the results found elsewhere. ${ }^{[1,8]} \mathrm{An}$ average of 1.5 injuries per match in this study is lower than some other studies ${ }^{[4,6,8]}$ although the differing methods of reporting make comparisons difficult. There was no way of logistically recording time exposure of each of the injured players individually, thus injuries could not be reported as per hour units of exposure.

The festival is unique for a number of reasons, which make these data difficult to compare to others. Players play three matches over 3 days on the Easter weekend. One could theorise that perhaps injuries would have been higher on the first day, with increased vigour and excitement of the participating players; alternatively the third day could be a more vulnerable time due to player fatigue. However, the results show that there was no significant difference in the frequency of injuries on any of the 3 festival days. The fact that there were also no differences between days across the 2 years supports this.

The majority of injuries were of the head and face followed by the lower limbs, which is different to some previous data indicating the lower limbs to be the most likely followed by the head and neck. ${ }^{[3,4,5]}$ However, there is another study with similar data. ${ }^{[6]}$ In children the head size is relatively large compared to the total body, and there is an increased head-neck girth that may explain more head and headrelated injuries in younger players. Our data are similar to those found in adult rugby players, possibly due to the participants being in the latter years of schooling and their ages closer to reported adult players. Further, changes in refereeing and or coaching may influence the site of injury, but cannot be determined. Law changes related to tackles and to scrums at the time may also have played a role.

In chronic and/or overuse injuries, having had a similar previous injury is a known risk for another similar injury occurring and is a trend also found in young players. ${ }^{[15]}$ However this was not the case in the setting of acute traumatic injuries typically sustained in the rugby festivals, where it was shown that there was no significant history of a previous similar injury having occurred.

Other expected results that conform to the literature are that tackles are the most common mechanism of injury at $48-60 \%$ of all injuries compared with $55 \%$ of injuries over one rugby season occurred in tackles as reported previously. ${ }^{[4]}$ Injury severity was difficult to compare to previous literature as there was no follow up in the cases in this study compared with more controlled environments. Fortunately there were no catastrophic neck injuries in the study cohort. Most management of injuries at the rugby festivals required basic first aid (RICE), to reduce swelling and pain. This was followed by referral for soft tissue therapy using physiotherapy and medication. This was appropriate for soft tissue injuries of ligaments, muscles and contusions as seen in similar studies. ${ }^{[16,17]}$

Along with the minor nature of most injuries there were very few referrals for radiographs. There were more referrals in year 2 despite there being less fractures and dislocations in that year. The difference cannot thus be explained by the type of injury nor the clinical criteria for referral, which would have been similar in both years. One can only conclude that the level of injuries was different, such that where there were ligament injuries they did not appear to have bony pathology associated with them, or were not of a nature or severe enough to cause joint instability. Why that should be different over the two festivals is unclear. Parent or coach pressure for the young players to return to play is a factor in this rugby festival environment that may have influenced the decision to conduct an investigation. Thus medical personnel may refer for investigations to exclude radiologically evident pathology.

\section{Conclusion}

Rugby is a collision sport and as such injuries do occur and can range in severity from minor to catastrophic. The Easter Rugby Festival, a schoolboy event studied in this paper, recorded an injury rate of 1.6 per match, most of which were to soft tissue and could be handled on the side of the field. This may be due to good facilities and referees at the festival. Other schoolboy rugby events without the same good resources may have differing results and more research is required to document whether the facilities and referees do indeed have a significant role to play in preventing severe injury in rugby matches.

\section{References}

1. Nicol A, Pollock A, Kirkwood G, Parekh N, Robson J. Rugby union injuries in Scottish schools. J Pub Health 2011;33(2):256-261. [http://dx.doi.org/10.1093/pubmed/fdq047]

2. Quarrie KL, Cantu RC, Chalmers DJ. Rugby union injuries to the cervical spine and spinal cord. Sports Med 2002;32(10):633-653. [http://dx.doi.org/10.2165/00007256200232100-00003]

3. Lee AJ, Garraway WM. Epidemiological comparison of injuries in school and senior club rugby. Br J Sports Med 1996;30(3):213-217. [http://dx.doi.org/10.1136/ bjsm.30.3.213]

4. Roux CE, Goedeke R, Visser GR, van Zyl WA, Noakes TD. The epidemiology of schoolboy rugby injuries. S Afr Med J 1987;71(5):307-313.

5. Nathan M, Goedeke R, Noakes TD. The incidence and nature of rugby injuries experienced at one school during the 1982 rugby season. S Afr Med J 1983;64(4):132-137.

6. Davidson RM. Schoolboy Rugby injuries, 1969-1986. Med J Aust 1987;147(3):119-120.

7. Freitag A, Kirkwood G, Scharer S, Ofori-Asenso R, Pollock AM. Systematic review of rugby injuries in children and adolescents under 21 years. Br J Sports Med 2015;49(8):511-519. [http://dx.doi.org/10.1136/bjsports-2014-093684]

8. Parekh N, Hodges SD, Pollock AM, Kirkwood G. Communicating the risk of injury in schoolboy rugby: using Poisson probability as an alternative presentation of the epidemiology. Br J Sports Med 2011;46(8):611-613. [http://dx.doi.org/10.1136/ bjsports-2011-090431]

9. Davidson R, Kennedy MJ, Vanderfield G. Casualty room presentations and schoolboy rugby union. Med J Aust 1978;1(5):247-249.

10. Macintosh AS. Rugby injuries. In: CD Maffulli N, ed. Epidemiology of Pediatric Sports Injuries: Team Sports. Basel: Karcher; 2005:120-139.

11. Burger N, Lambert MI, Viljoen W, Brown JC, Readhead C, Hendricks S. Tacklerelated injury rates and nature of injuries in South African Youth Week tournament rugby union players (under-13 to under-18): An observational cohort study. Br Med J Open 2014;4(8):e005556. [http://dx.doi.org/10.1136/bmjopen-2014-005556]

12. Krause LM, Naughton GA, Denny G, Patton D, Hartwig T, Gabbett TJ. Understanding mismatches in body size, speed and power among adolescent rugby union players. J Sci Med Sport 2014;18(3):358-363. [http://dx.doi.org/10.1016/j.jsams.2014.05.012]

13. Brown J, Verhagen E, Viljoen W, et al. The incidence and severity of injuries at the 2011 South African Rugby Union (SARU) Youth Week tournaments. S Afr J Sports Med 2012;24(2):49-54.

14. Fuller CW, Brooks JH, Cancea RJ, Hall J, Kemp SP. Contact events in rugby union and their propensity to cause injury. Br J Sports Med 2007;41(12):862-867. [http://dx.doi. org/10.1136/bjsm.2007.037499]

15. Hagglund $M$, Walden M, Ekstrand J. Previous injury as a risk factor for injury in elite football: A prospective study over two consecutive seasons. Br J Sports Med 2006;40(9):767-772. [http://dx.doi.org/10.1136/bjsm.2006.026609]

16. Bleakley CM, O'Connor S, Tully MA, Rocke LG, Macauley DC, McDonough SM. The PRICE study (Protection Rest Ice Compression Elevation): Design of a randomised controlled trial comparing standard versus cryokinetic ice applications in the management of acute ankle sprain. BMC Musculoskelet Disord 2007;19(8):125. [http://dx.doi.org/10.1186/1471-2474-8-125]

17. Laskowski ER, Najarian MM, Smith AM, Stuart MJ, Friend JF. Medical coverage for multievent sports competition: A comprehensive analysis of injuries in the 1994 Star of the North Summer Games. Mayo Clin Proc 1995;70(6):549-555. [http://dx.doi. org/10.4065/70.6.549] 